\title{
Conceito atual de demência precoce
}

\author{
Pelo Prof. Dr. Henrique Roxo \\ Catedrático de Clínica Psiquiátrica e Diretor do Instituto de Psicopatologia
}

Arquivos Brasileiros de Neuriatria e Psiquiatria, Rio de Janeiro, n.2, set.-out. 1929, p.79-91

\section{u u UUU}

O tema que foi formulado pelo sábio Mestre Prof. Miguel Couto, a ser debatido por mim, é um dos mais interessantes e dos mais complexos da psiquiatria hodierna. Depois de haver o Prof. Kraepelin, numa visão genial, estabelecido o conceito da demência precoce, este diagnóstico de tal forma se generalizou que as estatísticas dos nosocômios avultaram em dementes precoces. Hoje em dia, depois de haver o Prof. Bleuler fundamentado a esquizofrenia, sucede com a demência precoce o mesmo que com a histeria, de que só raramente se vê um diagnóstico firmado. Verdade é que Bleuler não acabou com a demência precoce e sim, substituiu o seu conceito pelo da esquizofrenia que muito amplia o daquela.

Ampliou, porém, de tal forma, que como esquizofrênicos são por ele tidos doentes que figuram comumente como maníaco-depressivos, confusos mentais, paranoicos, histéricos, desequilibrados, etc.

No Diário de Medicina de 10 de Dezembro de 1925 escrevi um artigo, em que fiz uma crítica da interpretação de Bleuler que, ao meu ver, peca por ser muito generalizadora. Já anteriormente o Prof. Claude discordara das ideias Bleulerianas, no meu entender com muita razão de ser.

Para que se possa bem compreender a profunda modificação que as ideias de Bleuler vieram trazer á interpretação da demência precoce, farei previamente uma síntese do que Kraepelin estabelecia.

O notável e pranteado Professor de Munich concebeu a demência precoce como uma entidade clínica, com predicados próprios, que fundamentou em 1889. Admitia três modalidades clinicas: a hebefrênica, a catatônica e a paranoide e considerava como predicado comum essencial o se estabelecer sempre um estado particular de enfraquecimento de inteligência.

Durante todo o decurso da doença há numerosas alucinações e numa aparência de completo alheamento, muitas vezes, ao que se lhes diz, percebem, porém, os doentes o que em torno deles se passa e se conservam orientados.

Um ponto importante, assinalado por Kraepelin, é ser o conteúdo das vozes absurdo e pueril, o que comprova o déficit mental que desde cedo se vai constituindo. Condição fundamental é também a falta de interesse pelas coisas do meio social e do meio familiar.

N.E. - Sobre este artigo, ver, "Classificando diferenças: as categorias demência precoce e esquizofrenia por psiquiatras brasileiros na década de 1920", de Ana Teresa A. Venancio, neste número de História, Ciências, Saúde - Manguinhos. 
O demente precoce vive engolfado em seu delírio, vivendo acordado dentro de seu sonho. Preocupado com ele, pode viver desatento, não sendo, no entanto, um confuso no rigor do termo.

A designação - demência precoce - é má, pois dá ideia de uma falta de memória que viesse muito cedo, e isto não sucede. Não há esquecimento e pode advir o mal tardiamente.

Um encadeamento lógico e perfeito se não vê no delírio, em que há uma desordem ideativa. Isto se justifica pelo abaixamento do nível intelectual.

Pelo mesmo motivo, muito se mostra comprometida a capacidade de autocrítica. Kraepelin julgava essencial na demência precoce a modificação da vida emotiva, verificando-se sempre uma obtusão emotiva de grau mais ou menos acentuado. Esta obtusão emotiva se manifesta de preferência em relação às pessoas mais íntimas e é de ver o doente repelir com ódio o pai e conversar com atenção com um criado.

Há falta de compaixão pelo sofrimento alheio, falta de pudor, indiferença pelas convenções sociais.

Na conduta do indivíduo há uma profunda modificação, havendo uma diminuição de todos os estímulos volitivos.

Esta dificuldade no agir contrasta muitas vezes com impulsos, em que o individuo investe inopinadamente contra pessoas que nenhum mal lhe fizeram.

Outro predicado constante é a perda da unidade interna da atividade intelectual, afetiva e volitiva, havendo uma desproporção e desconexão entre o sentir, o pensar e o querer. O doente ri quando houver motivo para ficar sério ou chorar, ou chora quando se trata de uma coisa alegre. Frequentemente há a sensação de uma influência estranha a agir sobre os atos. Múltiplos distúrbios de cenestesia se ostentam.

$\mathrm{Na}$ forma hebefrênica há numerosos distúrbios psicosensoriais que entretêm um delírio, mal sistematizado, em que ideias absurdas de perseguição, grandeza, etc. dominam o indivíduo.

$\mathrm{Na}$ forma catatônica, além dos distúrbios psicosensoriais, há principalmente perturbações motoras. Nestas são características a sugestibilidade, estereotipia, negativismo e impulsos.

$\mathrm{Na}$ forma paranoide há ideias delirantes, com o delírio de posse física, e o fenômeno do eco do pensamento.

Bleuler, fundamentando seu conceito nas esquizofrenias, diz que se não deve considerá-las como uma enfermidade no sentido rigoroso da palavra, mas como um grupo patológico, em que há como predicados particulares a dissociação mental e uma alteração nas relações com o mundo exterior.

O termo esquizofrenia significaria loucura com dissociação. Diz Bleuler ser o termo muito melhor do que o de demência precoce. Nesta não há, com efeito, alteração da memória e nem sempre vem muito cedo.

O essencial seria sempre a desconexão e a falta de adaptação ao meio e onde quer que isso se encontrasse haveria esquizofrenia, que assim passou a constituir um grupo muito vasto de doenças mentais.

Nelas ocorrem condensações ou fusões de ideias que deveriam ficar destacadas.

Há um vício fundamental na ligação de ideias para formar o raciocínio. Não é a lógica que nelas influi, e sim desejos e temores que dominam a afetividade do indivíduo. De fato, o sentir se mostra profundamente perturbado e há particularmente uma profunda desproporção nos sentimentos. 
Muito frequente é a sensação de já não ser senhor do seu pensamento e de o obrigarem a pensar naquilo, em que o não queira fazer.

O sintoma mais impressionante de esquizofrenia é a demência afetiva. Lembra muito bem Bleuler que nos asilos há doentes que não mostram sentimento algum, suceda o que suceder a ele ou aos que o rodeiem.

Um dos sinais mais característicos da doença é um defeito na capacidade de modulação afetiva, uma verdadeira rigidez afetiva.

O doente não varia o seu modo de sentir, de acordo com a intensidade e qualidade das sensações que vá experimentando. Os assuntos de que trata, lhe não causam grande mossa.

A notícia de morte de um ente querido deixa-os indiferentes. Curioso é poder reaparecer a afetividade, se uma afecção orgânica como a atrofia senil, a apoplexia, etc., se complicar com a esquizofrenia.

No tocante à afetividade, há quem queira contestar que na demência precoce haja realmente perda da afetividade. Uma doente, por exemplo, que tinha muita raiva da própria mãe, vivia num sonho acordado a idealizar o seu amor ao namorado cujo casamento havia sido contrariado. Amava-o deveras e continuava a amá-lo. Exercem na demência precoce influência indiscutível os complexos que representam um conjunto de ideias fortemente impregnadas de um coeficiente afetivo.

Haveria antes uma desproporção afetiva e grandes amores coincidiriam com grandes ódios. No entanto, não me parece que a esquizofrenia deva ser tida como uma doença da afetividade, unicamente pela existência de uma anomalia afetiva que faz o doente deixar de querer bem a quem normalmente todos querem bem. Com a evolução da demência precoce a afetividade vai morrendo, cada vez vai havendo maior desinteresse afetivo e dia a dia o demente precoce se vai encastelando dentro do seu sonho acordado que é o único lugar, em que o sentimento não morre.

Na demência precoce tudo é questão de falta de utilização prática, de carência de atividade pragmática.

Não sabe retribuir devidamente a estima das pessoas que o rodeiam. Não sabe aplicar o seu afeto ao meio ambiente.

O autismo domina o quadro clínico da esquizofrenia. Dia a dia o doente se vai desinteressando do meio ambiente e procurando viver dentro do seu sonho.

Gosta de se isolar. Evita as conversas. Existe um contraste entre a felicidade que lhe dá sua imaginação, e o desagrado que lhe traz o meio ambiente. Há uma grande falta de interesse pelo mundo que sempre se lhe antolha sob um prisma tão desagradável. Doença da vontade pode traduzir-se não só pela falta de iniciativa, como pela esquisitice do querer, como pela repetição de um ato, sem motivo plausível para isso.

Há um vício na associação de ideias dos esquizofrênicos. A falta de clareza de raciocínio e de objetivos pode conduzir a resultados contraditórios, ilógicos, pueris. Há associação extravagante de ideias. O esquizofrênico que diz uma porção de coisas sem nexo deixa, porém, perceber aqui e ali um fragmento do pensamento sexual que o domina.

Há muitas alucinações, predominantemente do ouvido e da cenestesia.

As ideias delirantes são contraditórias, ilógicas. Os maiores absurdos podem constituir o delírio. 
As desordens nas associações de ideias e as sensações cinestésicas patológicas fazem com que o esquizofrênico se sinta diferente do que era anteriormente, sinta a sua pessoa mudada.

As mais diversas diestesias fazem com que o doente se sinta influenciado.

O delírio de perseguição coincide frequentemente com o de influência física. Bleuler admite quatro grupos de doentes esquizofrênicos: os simples esquizofrênicos, os hebefrênicos, os catatônicos e os paranoides.

Ampliando o conceito da esquizofrenia, diz textualmente Bleuler, ficam pertencendo à esquizofrenia muitas manias e melancolias não puras de outras escolas (provavelmente as manias e melancolias histéricas), a maior parte das confusões alucinatórias, muito do que os autores chamam amentia, uma parte das formas que foram atribuídas ao delírio agudo, as psicoses de motibilidade de Wernicke, demências primitivas ou secundarias sem nome especial, a maior parte das paranoias das outras escolas, especialmente todas as psicoses histéricas, quase todas as hipocondrias incuráveis e muitos pacientes nervosos, psicastênicos e impulsivos. Acrescenta ainda Bleuler às formas juvenis e masturbatórias elevadas à categoria de enfermidades especiais, uma grande parte das psicoses da puberdade e das psicoses degenerativas de Magnan, muitas psicoses de reclusão e estados crepusculares de Ganser. Diz, outrossim, Bleuler que são muito frequentes as esquizofrenias latentes, de tal modo que a enfermidade esquizofrenia é um conceito mais amplo que a psicose manifesta do mesmo nome.

Bleuler admite quatro subgrupos principais de esquizofrenia: a simples, a hebefrênica, a catatônica e a paranoide. Em qualquer doente as alucinações cenestésicas ocupam lugar saliente.

Os distúrbios catatônicos são também muito comuns. Bleuler assinala que dos sintomas somáticos apenas a ausência de reação pupilar psíquica tem significação especial.

Diz ele que excluir diretamente uma esquizofrenia nunca se poderá fazer.

Frisa ele que a esquizofrenia se associa frequentemente a psicoses orgânicas quando estas surgem em indivíduo esquizoide, isto é, portador de uma esquizofrenia latente, e particularmente com a psicose maníaco-depressiva.

A esquizofrenia é uma afecção de base orgânica que surge em uma pessoa predisposta por uma enfermidade constitucional, havendo sempre uma superestrutura psicógena considerável, isto é, um distúrbio geral da vida psíquica que vai até a vida dos instintos.

No trigésimo congresso de alienistas e neurologistas franceses, reunido em Lausanne de 2 a 7 de Agosto de 1926, o Prof. Henri Claude apresentou o seu conceito da esquizofrenia, no qual discorda em vários pontos das ideias de Bleuler.

Diz que admite o tipo do esquizoide, do esquizomaníaco e do esquizofrênico propriamente dito. No tipo do esquizoide, muito bem delineado por Kretschmer em 1921, haveria um caráter insociável, em que o indivíduo viveria como concentrado dentro de seus sonhos, idealizando uma vida muito outra da realidade e desagradado constantemente da vida social. Uma pessoa pode atravessar sua vida inteira com um feitio esquizoide e nada lhe acontecer. Se surgirem, porém, contrariedades provocadas pelo meio social, a adaptação que a custo se realizara em relação a este, se rompe e o individuo se torna um esquizomaníaco. O conceito de esquizomania de Claude se aproxima, até certo ponto, do das catafrenias, há anos, muito anteriormente, fundamentado pelo talentoso Prof. Austregésilo.

Da esquizomania pode passar o doente à esquizofrenia, o que segundo Claude, pode, às vezes, ocorrer no fim de 20 a 30 anos. Claude pensa que a esquizofrenia seja uma aberração mental 
funcional. Causas morais concorrem, poderosamente, para que ela se manifeste. Quando há apenas um distúrbio funcional, há rigorosamente esquizofrenia; quando, porém, se instala uma lesão cerebral, em que há principalmente uma atrofia celular cerebral, há a demência precoce. Claude assinala que a demência precoce é uma doença dos moços e que a esquizomania e a esquizofrenia podem surgir mesmo em idade avançada. O que não é possível é ser esquizofrênico ou esquizomaníaco sem que antes se seja esquizoide. Na esquizofrenia, propriamente dita, haveria muito pensamento recalcado, o doente teria uma ideia obsessiva, frequentemente de natureza sexual, em torno da qual se agrupariam outros, havendo um estado de autismo, de concentração interior, em que o indivíduo viveria como num sonho acordado. Na verdadeira forma de demência precoce haveria uma atrofia celular cerebral, posterior a uma meningoencefalite circunscrita, $\mathrm{e}$ um déficit mental coincidiria com a ausência de pensamentos recalcados.

O Prof. Henri Claude e Gilbert Robin conseguiram separar uma forma clínica da outra por meio de eterização.

Entonteceria os doentes pelo éter e num caso, fazendo perguntas, obteria dentro de pouco tempo respostas, em que transpareceria o que estava incomodando o doente. Isto no caso da esquizofrenia propriamente dita. No caso da demência precoce não haveria pensamento algum recalcado: o cérebro se mostraria vazio de ideias. Haveria um verdadeiro deserto afetivo e se patentearia a desagregação da esfera psíquica.

$\mathrm{Na}$ esquizofrenia haveria sempre uma ruptura de equilíbrio na síntese das funções mentais e um deslocamento de natureza afetiva entre a atividade prática, o pragmatismo nulo [ilegível], desordenado, e a atividade intelectual conservada e a se exercer no autismo, no revolver um pensamento torturante. Num caso não há falta de inteligência, apenas é ela mal aplicada; no outro há pobreza mental.

Bornszetaju, de Varsóvia, no Congresso Médico lá reunido de 12 a 16 de Julho de 1926, falou na "esquizotimia reativa circunscrita" que descrevera em 1916 e em que havia uma forma reacional de esquizofrenia e lembrou que em 1922 descrevera casos que se iniciaram por simples obsessões.

Assinalou ele que a esfera afetiva está em ligação muito estreita com o sistema vegetativo. A adaptação à vida e ao ambiente dependeria do funcionamento harmônico do sistema vegetativo ou afetivo-instintivo de um lado e do intelectual, do outro.

A constituição esquizoide se formaria quando a esfera instintivo-afetiva tendesse a se libertar do controle indispensável da esfera intelectual.

Quando houver uma alteração profunda na esfera instintivo-afetiva, isto é, no sistema vegetativo, haverá também distúrbios endocrínicos, por isso que há uma ligação muito estreita entre os dois sistemas. Os distúrbios no sistema vegetativo e no endocrínico vão atuar sobre o sistema nervoso central e lesões anatômicas mais ou menos acentuados se formarão nos núcleos centrais e na cadeia cerebral.

Minkowski, na sessão da Sociedade Médico Psicológica de Paris, de 22 de fevereiro de 1926, analisando o conceito de Bleuler, diz que este estabelece como fundamental um relaxamento das associações, uma dissociação psíquica, ao passo que ele estabelece como fundamento do seu conceito a perda de contato vital com a realidade.

Interessante é confessar Minkowski que de tal forma generaliza Bleuler o seu tipo de esquizofrênico que em Zurique quando se desce do trem, já o viajante fica classificado, pelo menos, entre os esquizofrênicos latentes. 
A ambivalência que consiste em querer uma coisa e ao mesmo tempo deixar de querer, em gostar de uma pessoa e a odiar, minutos depois, em viver hesitando entre o que fazer e o que deixar de fazer, é para Bleuler predicado dos mais essenciais na esquizofrenia. Nela existe um defeito mental que faz com que coisas contraditórias que normalmente se excluem, possam viver na mentalidade uma ao lado da outra. Com frequência se entremeiam ideias alegres e tristes.

Pode-se dizer, em síntese, que na esquizofrenia fundamentada por Bleuler há sintomas cardeais e sintomas secundários ou acessórios. Entre os primeiros se contariam: a perda de contato com a realidade e o pensamento autístico, dele dependente, a dissociação psíquica, os distúrbios afetivos e a ambivalência; entre os secundários, as alucinações, as ideias delirantes, a sindrome catatônica, síndromes agudas maníacas e confusionais, etc. Na esquizofrenia latente ou frusta há quase exclusivamente os sintomas capitais. O doente não é um alucinado, muitas vezes não é um delirante. Aquilo que é essencial é ser dissociado, autista e ambivalente.

Wizel, nos Annales Médico-psychologiques de Maio de 1926, frisa muito bem que os esquizofrênicos latentes conservam muitas vezes completa lucidez, perfeita orientação e, frequentemente, consciência do seu estado de doença.

O termo de esquizofrenia que significa loucura com dissociação, é evidentemente superior ao de demência precoce que no caso se aplica a uma doença, em que não há perda de memória e em que o aparecimento não vem cedo, muitas vezes.

O professor de Psiquiatria da Bolívia Cesar Adriazole escreveu em Fevereiro de 1928 um artigo muito interessante a respeito da "Confederação Esquizofrênica" em que muito bem assinala que a memória e a orientação se mantêm quase intactas, ao passo que há sempre uma dissociação ou deslocamento do pensamento e da personalidade, um modo paratímico de ser e agir (ambivalências) e uma afetividade indiferente ou embotada.

Em Agosto de 1927, na Revista Argentina de Neurologia, Psiquiatria e Medicina Legal, o Prof. Nerio Rojas e o Dr. José Belbey, psiquiatras argentinos de grande competência, assinalam o receio de que, muito generalizado o conceito, venha a ser aplicado o titulo de esquizofrenia a coisas heterogêneas e que possa ele vir a receber as mesmas críticas que o de demência precoce que visou substituir.

Curioso é que aqueles que se mostram mais entusiastas da integridade do conceito bleuleriano como o professor boliviano Cesar Adriazola, são forçados a apelar para uma questão de psicose associada nos casos em que, por exemplo, uma histérica deve ser tida como esquizofrênica.

Bleuler chama bem a atenção para a questão das psicoses associadas e diz que a esquizofrenia se pode combinar com a oligofrenia, com a psicose senil, com o alcoolismo, com a epilepsia, com a psicose maníaco-depressiva, etc., e é ele próprio quem assinala que a combinação nem sempre fica bem caracterizada e que a limitação do que cabe à demência precoce, nem sempre fica bem nítida.

O essencial na esquizofrenia é sempre a ruptura entre a camada superficial das funções elementares do espírito e o núcleo profundo constituído pelo eu. Aquela não se acha profundamente alterada, apenas perde as relações com este. É uma verdadeira dissociação intrapsíquica.

Perde-se o interesse pelas coisas do mundo real. O doente se engolfa num sonho acordado. Há uma verdadeira loucura discordante no excelente conceito de Chaslin. 
O desaparecimento da afetividade depende, segundo Bleuler, de um complexo que se forma, no qual se acumula toda a carga afetiva do doente, rompendo-se assim, por esta concentração os laços com o resto do psiquismo. Vê-se por aí que no entender de Bleuler se não pode a rigor dizer que na esquizofrenia haja ausência de afetividade e sim a má aplicação dela.

Rumke, em excelente trabalho de Dezembro de 1928, no "Psychiatrische en Neurologische Bladen", diz que se deve distinguir uma esquizofrenia clássica que corresponde à demência precoce de Kraepelin, de reações de aparência esquizofrênica. Como bem se vê ele fica mais ou menos de acordo com Claude.

Claude acredita que na verdadeira demência precoce haja um estado de decadência intelectual, ligado a uma distrofia dos elementos nobres do encéfalo ou a um distúrbio funcional deles dependente de uma alteração glandular, de uma autointoxicação (demência neuroepitelial de Klippel e Lhermitte). As manifestações psíquicas dependem segundo Josephy, de lesões finas das células de certas camadas da côdea cerebral.

Em última análise há, no dizer de Claude, uma encefalite crônica.

Em trabalho no Paris-Medical de 18 de Outubro de 1924, a respeito da Catatonia, diz ele que há nela lesões dos núcleos cinzentos centrais, particularmente do pallidum. Interessante é que vários trabalhos foram realizados, assinalando as relações existentes entre a demência precoce e a encefalite epidêmica, da qual, em interessante conferência, o Prof. Marinsco também aproximara à histeria.

Segundo Claude, os núcleos de base representariam centros motores intencionais justapostos aos centros corticais de inervação, o que explicaria a simultaneidade dos fenômenos psíquicos e motores e de intrincação psicomotora complexa.

Para focalizar e bem esclarecer a questão do conceito atual da demência precoce, pode-se sintetizar em poucas palavras que há três doutrinas a respeito: a de Kraepelin, a de Bleuler e a de Claude. Kraepelin assinalava como predicados fundamentais diminuição da inteligência, profunda modificação da afetividade, enfraquecimento da capacidade volitiva.

Bleuler dá como essencial, haver dissociação mental, ambivalência, autismo, falta de atividade pragmática.

Claude admite uma transição do esquizoide para esquizomaníaco e esquizofrênico. Pensa que a esquizofrenia seja uma aberração mental funcional e que só haja verdadeiramente demência precoce quando coexistir abaixamento notável da capacidade intelectual, dependente de uma atrofia celular cerebral.

Acho que Claude tem razão e penso que Bleuler generaliza demais.

Não acho razoável colocar como esquizofrênicos doentes de paranoia, histeria, confusão mental, delírios sistematizados alucinatórios, mania, melancolia, etc.

Se a dissociação psíquica, a ambivalência e o autismo representam fenômenos capitais na demência precoce, é preciso que esses termos tenham sua significação bem precisa e restrita. $\mathrm{Na}$ dissociação psíquica há essencialmente falta de ligação nas ideias em relação ao sentimento e à ação. Penso ser essencial na demência precoce a falta de afetividade. Aliás, é o próprio Bleuler quem diz que o sintoma mais impressionante da esquizofrenia é a demência afetiva. No entanto, admitindo que haja sempre uma forte carga afetiva em relação a um assunto qualquer, a uma dada pessoa, seria unilateral na afetividade, mas até certo ponto muito intenso nesta. 
Não penso que isto seja o que se observa. Aquilo que em geral se constata, é o demente precoce não fazer caso dos pais, dos irmãos e das pessoas que normalmente mais se estimam. Pode suceder que os afague, mas que os acompanhe nos dias de sofrimento ou que chore sentidamente pela morte deles, nunca vi. Se ele viver apaixonado por uma mulher e com ela tiver uma vida imaginária, sexual, toda espiritual, a presença real dela não o fará vibrar.

É sempre fundamental a falta de atividade pragmática a falta de utilização, de aproveitamento na ação.

Lembro-me bem de um cliente esquizofrênico que falava repetidamente em uma mulher, única com a qual conseguira ter uma vida sexual perfeita. Quando o pai conseguiu que o encontro entre os dois se realizasse, ele mostrou-se absolutamente desinteressado.

Assinala-se o fato de que há muitas vezes uma contrariedade amorosa, uma ideia afetiva recalcada, no início do mal. Muito afeto unilateral, concentrado, portanto. No entanto, como muito bem se vê no exemplo acima referido, quando se trata de comprovar o sentimento, ele falha na sua exteriorização.

O pensamento fica como um elemento torturante. Não é uma coisa que dê prazer, que dê gozo. A prova de que o indivíduo esquizofrênico tenha um exagero de afetividade, parece não poder ser dada.

Do mesmo modo, a ambivalência precisa ter sua significação bem precisa. Consiste ela essencialmente em que coisas contraditórias que normalmente se excluem, coexistiriam na ocasião.

Assim é o indivíduo que chora e ri ao mesmo tempo, que estende a mão e a recua, que quer uma coisa e logo a recusa, que pensa em ser um homem como os outros e ao mesmo tempo em ser bem diferente, etc. Há uma ambivalência afetiva, uma intelectual, uma voluntária (ambitendência).

Sempre na ambivalência há a testemunha de dissociação e irresolução. Pelo fato de não haver uma boa ligação das ideias, o pensamento se não estabiliza e se torna possível logo se apresentar a ideia contrária e o indivíduo fica na dúvida. Quando este feitio não se anteolhar, não há ambivalência.

O autismo deve igualmente apresentar-se com todos os seus caracteres.

O indivíduo viverá, no caso, dentro de si mesmo, isolado do mundo exterior, engolfado em seus pensamentos. Frequentemente alucinado, vê-se o doente a falar sozinho, a dialogar com as pessoas que julga escutar, num outro mundo que não o real.

No conceito atual da demência precoce muito influiu a doutrina de Freud. Ela teve o valor inestimável de chamar a atenção para os complexos recalcados, para o pensamento oculto que tortura o doente e orienta toda a sua conduta. E acredito que a doutrina de Claude possa influenciar bem uma boa terapêutica.

Se se tratar de um verdadeiro demente precoce, com atrofia das células cerebrais, com placas de meningoencefaltie crônica, com alterações profundas dos optoestriados, com diminuição notável da capacidade intelectual, o tratamento quase nada poderá conseguir. No caso em questão, emprego do iodinjectol, a vitamina, a opoterapia pluriglandular, a lecitina, o arsênico, os fosfatos em geral.

Se se tratar, porém, de um esquizofrênico, isto é, se se tratar de um demente precoce sem falta de inteligência, sem atrofia de células do cérebro e lesões inflamatórias crônicas, muito se poderá 
conseguir. Deve-se investigar qual o pensamento dominante no doente, e se se tratar de uma coisa que pelos seus conselhos, pela sua persuasão, o médico possa remover, ele o fará. Se a remoção do motivo não estiver ao seu alcance, ele usará a terapêutica pelo trabalho. Esta distrairá o doente, particularmente se se lhe der um serviço que não seja enfadonho e ao qual ele se deva dedicar com a obrigatoriedade de o entregar em data fixa. Os remédios que preconizei para a verdadeira demência precoce, evidentemente aqui melhor servirão. No entanto, é preciso bem frisar que a derivação intelectual é recurso de extraordinário valor. Penso que a esquizofrenia é um mal curável.

\section{Conclusões}

Penso que o conceito bleuleriano de esquizofrenia generaliza demais.

Acho que Claude tem razão quando admite o tipo do esquizofrênico propriamente dito, sem diminuição da capacidade intelectual e sem lesão grave cerebral, e o tipo do verdadeiro demente precoce, com falta de inteligência e atrofia das células cerebrais.

No esquizofrênico muito aproveita a psicanálise e é muito aconselhável a terapêutica pelo trabalho.

No demente precoce típico, o iodo, as vitaminas e a opoterapia são os recursos com os quais se poderá conseguir alguma coisa.

Relatório apresentado ao $3^{\circ}$ Congresso de Neurologia, Psiquiatria e Medicina Legal.

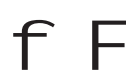

